\title{
OS PRINCÍPIOS CONSTITUCIONAIS ENTRE DEONTOLOGIA E AXIOLOGIA: PRESSUPOSTOS PARA UMA TEORIA HERMENÊUTICA DEMOCRÁTICA
}

\author{
Fábio Portela Lopes de Almeida ${ }^{1}$ \\ THE CONSTITUTIONAL PRINCIPLES BETWEEN DEONTOLOGY \\ AND AXIOLOGY: THEORETICAL ASSUMPTIONS TOWARDS \\ A DEMOCRATIC HERMENEUTIC THEORY
}

\section{RESUMO}

O ARTIGO TEM POR PROPÓSITO DISCUTIR A NATUREZA DOS PRINCÍPIOS CONSTITUCIONAIS A PARTIR DE DUAS TEORIAS HERMENÊUTICAS DISTINTAS: A AXIOLOGIA E A DEONTOLOGIA. A PERSPECTIVA AXIOLÓGICA É DESCRITA A PARTIR DA TEORIA DOS PRINCÍPIOS DELINEADA POR ROBERT ALEXY EM SUA TEORIA DOS DIREITOS FUNDAMENTAIS E CRITICADA POR SER INCAPAZ DE LIDAR DEMOCRATICAMENTE COM O FATO DO PLURALISMO, ISTO É, COM A CIRCUNSTÂNCIA DE QUE AS SOCIEDADES CONTEMPORÂNEAS NÃO SE ESTRUTURAM EM TORNO DE VALORES ÉTICOS COMPARTILHADOS INTERSUBJETIVAMENTE POR TODOS OS CIDADĀOS. COMO ALTERNATIVA A ESSE MODELO, SUGERE-SE, A PARTIR DAS OBRAS DE JOHN RAWLS, Ronald DWORKIn E JÜRgen Habermas, QUe A ADOÇÃo DE UMA PERSPECTIVA DEONTOLÓGICA, QUE ASSUME A DISTINÇÃO ENTRE PRINCÍPIOS E VALORES, SUPERA AS DIFICULDADES DA TEORIA AXIOLÓGICA. AO ASSUMIR COMO PREMISSA CENTRAL A POSSIBILIDADE DE LEGITIMAÇÃO DO DIREITO A PARTIR DE PRINCÍPIOS JUSTIFICADOS A PARTIR DE CRITÉRIOS ACEITÁVEIS POR TODOS OS CIDADÃOS, UMA TEORIA DEONTOLÓGICA DOS PRINCÍPIOS SE TORNA CAPAZ DE LIDAR COM A PLURALIDADE DE CONCEPÇ̃̃ES DE BEM PRESENTES NAS SOCIEDADES CONTEMPORÂNEAS. NESSE SENTIDO, O ARTIGO SE SITUA NO CAMPO DE ESTUDOS PRÓPRIO DA TEORIA DA CONSTITUIC̣ÃO.

PALAVRAS-CHAVE

DEONTOLOGIA; AXIOLOGIA; LIBERALISMO; TEORIA DOS VALORES

\begin{abstract}
THE ARTICLE DISCUSSES THE NATURE OF THE CONSTITUTIONAL PRINCIPLES BY OPPOSING TWO DISTINCT HERMENEUTIC THEORIES: AXIOLOGY AND DEONTOLOGY. THE THEORY OF PRINCIPLES PROPOSED BY ROBERT ALEXY IS ASSUMED AS AN IDEAL EXAMPLE OF AXIOLOGICAL THEORY, AND CRITICIZED FOR BEING UNABLE TO DEAL DEMOCRATICALLY WITH THE FACT OF PLURALISM, I. E., THE FACT THAT THE CONTEMPORARY SOCIETIES ARE NOT STRUCTURED ON ETHICAL VALUES SHARED BY ALL THE CITIZENS. AS AN ALTERNATIVE TO THE AXIOLOGICAL MODEL, I SUGGEST, BASED ON A PARTICULAR READING OF THE THEORIES OF JOHN RAWLS, RONALD DWORKIN AND JÜRGEN HABERMAS, THAT THE ADOPTION OF A DEONTOLOGICAL PERSPECTIVE, WHICH ASSUMES A STRICT DISTINCTION BETWEEN PRINCIPLES AND VALUES, OVERCOMES THE DIFFICULTIES OF THE AXIOLOGICAL THEORY. ASSUMING AS A CENTRAL PREMISE THAT LAW IS LEGITIMIZED BECAUSE THE CITIZENS OF A CONSTITUTIONAL DEMOCRACY ACCEPT PRINCIPLES THAT ARE JUSTIFIED FROM WIDELLY RECOGNIZED CRITERIA, A DEONTOLOGICAL THEORY OF THE CONSTITUTIONAL PRINCIPLES TURNS TO BE ABLE TO DEAL WITH THE PLURALITY OF CONCEPTIONS OF THE GOOD PRESENT IN THE CONTEMPORARY SOCIETIES. IN THIS SENSE, THE ARTICLE DISCUSSES QUESTIONS RELATED TO THE CONSTITUTIONAL THEORY.

\section{KEYWORDS}

DEONTOLOGY; AXIOLOGY; LIBERALISM; THEORY OF VALUES
\end{abstract}

\section{INTRODUÇÃO}

A discussão a respeito da natureza dos princípios constitucionais depende do esclarecimento de diversas pressuposições acerca da hermenêutica constitucional. Nessa medida, é preciso avaliar qual seria a melhor teoria capaz de explicar e de instruir o 
modo pelo qual devemos interpretar os princípios constitucionais. Defender um dos lados do debate implica assumir uma série de pressupostos filosóficos controversos acerca da teoria do direito e da relação entre o direito e democracia. Implica, além disso, desenvolver uma resposta concreta a respeito do modo pelo qual a relação entre os valores morais e o direito deve se estabelecer. O direito é moral? Se os princípios constitucionais refletem os valores morais de um determinado povo, como eles alcançam aceitação geral se as sociedades multiculturais são caracterizadas justamente pelo fato de seus membros não compartilharem valores essenciais? Como uma constituição pode ser legítima num contexto pluralista? Estas perguntas difíceis dependem de uma resposta prévia à seguinte questão: qual a natureza dos princípios constitucionais?

Este artigo objetiva discutir duas teorias presentes neste debate: a perspectiva axiológica, defendida majoritariamente pela teoria constitucional alemã a partir de uma teoria comunitarista (BRUGGER, 2004, p. 431-60), e a perspectiva deontológica, cujas raízes fundamentais se encontram nas obras dos chamados liberais igualitários (egalitarians) e que se desenvolveu de forma mais profunda no constitucionalismo americano (RosENFELD, 2001, p. 1306-1351).

Com esse propósito, o artigo se desenvolve em duas seções. Na primeira, apresenta de maneira crítica a proposta teórica fornecida pela teoria axiológica, adotando-se como modelo o conceito de constituição desenvolvido por Robert Alexy em sua Teoria dos direitos fundamentais. Em seguida, após explicitar os pressupostos deste conceito de constituição, será apresentado um conceito distinto de constituição, baseado no modelo constitucional deontológico liberal. ${ }^{2}$

\section{A CONSTITUiÇÃO COMO UMA ORDEM CONCRETA DE VALORES: A TEORIA AXIOLÓGICA DOS DIREITOS FUNDAMENTAIS}

A problemática relação entre o direito e os valores morais tradicionais é questão permanente na história da filosofia jurídica. A rigor, desde a filosofia grega até o fim da Idade Média, é inquestionável a relação de dependência do direito em relação à eticidade da comunidade. Toda a tradição da filosofia moral e jurídica da Antigüidade e da Idade Média recorre aos valores éticos da comunidade para justificar a legitimidade do direito. Assim, essa tradição adota um conceito forte de virtude, necessário para se estabelecer a diferenciação entre os bons cidadãos da polis, portadores do caráter moral necessário para manter a existência pacífica e gloriosa da vida social, e os maus cidadãos, não-virtuosos, cuja simples existência é danosa à vida coletiva. Essa é a mensagem da república platônica: a vida coletiva deve ter como objetivo educar todos os cidadãos para viverem de acordo com as virtudes (temperança, coragem e sabedoria) necessárias para melhor cumprir o valor moral supremo da cidade: a realização da Idéia de Bem.

Praticamente toda a filosofia do direito e da moral até a idade moderna reflete o ideal de que a função do direito é assegurar a reprodução da vida social a partir da 
manutenção dos pressupostos axiológicos tradicionalmente fixados em uma ordem concreta de valores estabelecida historicamente. Daí a seguinte afirmação do sociólogo Niklas Luhmann:

Para a antiga tradição européia da filosofia social e da filosofia do direito era evidente que o homem encontrava sua liberdade e sua virtude, sua sorte e seu direito enquanto parte viva da sociedade também viva. A sociedade era vista como associação de homens concretos, muitas vezes explicitamente chamada de corpo social. Era exatamente por consistir de homens que ela apresentava seu humanismo evidente e abrangente, e sua pretensão moral. Nesse contexto, o ambiente da sociedade, sem se considerar a natureza não humana, só podia constituir-se de outras sociedades - ou seja, de corpos sociais formados por outros homens. Conseqüentemente, os limites da sociedade eram concebidos como limites da descendência ou dos limites territoriais que agrupavam os homens nas categorias de pertencentes ou não pertencentes (LuHMANn, 1983, p. 169).

Nesse contexto, o direito deve refletir os valores éticos compartilhados pela comunidade política, tendo por função garantir a mediação dos conflitos sociais a partir dos valores derivados da ética compartilhada por toda a comunidade política. É necessário garantir a permanência dos laços orgânicos de sustentação da vida comunitária, a partir do compartilhamento dos valores fundamentais por todos os membros do corpo social. Para assegurar a unidade social, torna-se imperativo o uso da coerção para impedir a possibilidade de dissenso daqueles que, por qualquer razão, deixam de partilhar os valores da vida ética de sua comunidade.

Para manter essa unidade, impõe-se a necessidade de restringir as escolhas morais dos indivíduos. Ao direito cabe proibir a adesão a valores morais diversos dos sustentados pela comunidade, assegurando-se a estabilidade dos valores supremos de uma determinada coletividade. Nesse contexto, identifica-se a fusão entre a faticidade das tradições e valores culturalmente estabilizados na vida social e a validade das pretensões morais dos integrantes da comunidade. Em outras palavras, o membro de uma comunidade pré-moderna orientava sua ação a partir das orientações axiológicas constituintes do seu mundo da vida, solidificadas a partir da tradição de sua comunidade. O dissenso e a crítica à tradição são vedados, já que as instituições da vida social protegem a validade dos valores tradicionais por meio da coerção jurídico-moral (HABERMAS, 1997, p. 42-43).

\section{I A desconstruÇão metaÉtica da teoria AXiológica}

A filosofia jurídica pré-moderna assume como pressuposto uma determinada teoria dos valores capaz de explicar a coordenação da integração da vida social. Antes de 
avaliar esta teoria, contudo, é necessário colocar em evidência alguns pressupostos da teoria axiológica, a partir de uma perspectiva metaética, ou seja, discutindo-se os elementos lógicos do discurso axiológico.

Dessa perspectiva, uma primeira consideração a ser feita é a seguinte: do ponto de vista moral, não existe apenas um único valor. Existem vários valores e, mais ainda, vários valores que podem entrar em conflito. Esta é uma tese metaética, pois dela decorre que qualquer teoria ética precisa reconhecer e lidar com esse problema.

Há duas maneiras diferentes de lidar com o fato da pluralidade dos valores morais. A primeira perspectiva, o "monismo", assume como pressuposto que, embora existam vários valores, há um único valor que é preponderante em relação aos demais. Uma teoria ética monista pode lidar com o conflito de valores de três maneiras distintas: determinar um summum bonum, admitir a fungibilidade dos valores ou adotar um critério último (canônico) de ordenação dos valores (KEKES, 1993, p. 63-75). A primeira versão da ética monista assume a existência de um prioritário em relação a todos os outros valores (o summum bonum), cujo principal paradigma é a ética platônica, que aceita o Bem como o valor fundamental da moralidade humana. Esse valor (o Bem) assume a função de ordenar todos os outros valores de modo a alcançar uma ordem coerente em que o conflito axiológico se torne apenas uma mera aparência. O monismo, nessa versão, é incapaz de reconhecer que exista, de fato, um conflito de valores: se há um summum bonum que organiza toda a moralidade, o fato de alguém acreditar que um valor está em conflito com outro não coloca em dúvida a estrutura dos valores. A percepção do conflito decorre de uma incapacidade intelectual do agente moral, que não enxerga a coerência do sistema ordenado dos valores morais e se engana pela aparência de conflito entre um valor e outro. A principal deficiência dessa perspectiva decorre da necessidade da adoção de uma teoria metafísica da moral, ao supor que existe uma ordem objetiva de valores independente, esperando ser "descoberta” pela razão humana.

Uma segunda versão do monismo aceita a fungibilidade entre os diversos valores. De acordo com esta versão, os valores não são incompatíveis entre si, porque os valores podem ser ordenados (ranked) a partir da tradução de cada valor em termos de uma unidade comum. Assim como podemos traduzir o valor econômico de um bem monetariamente, com a finalidade de facilitar a operação de troca, também podemos conhecer a importância de um determinado valor moral a partir do número de unidades morais que ele reflete. O número de unidades fornece uma medida comum de análise do conflito axiológico que, assim, também não passa de mera aparência. O utilitarismo hedonista de Jeremy Bentham exemplifica o modus operandi dessa perspectiva. De acordo com o filósofo inglês, o meio de comparação entre os vários valores é o prazer: um valor é melhor que o outro na medida em que traz como resultado mais prazer. Quanto mais prazer for gerado por um determinado valor, melhor 
ele é. Avaliar a melhor acomodação entre os valores pressupõe, assim, uma avaliação prévia a respeito de qual ajustamento é capaz de gerar mais prazer.

Quatro problemas principais são inerentes à perspectiva do utilitarismo hedonista. Em primeiro lugar, ela falha em reconhecer que simplesmente não existe uma "régua moral" capaz de traduzir os valores em termos de uma medida comum (utilidade ou prazer). Em segundo lugar, ela falha em reconhecer que os prazeres diferem entre si não apenas quantitativamente, mas também qualitativamente. Uma pequena quantidade de um determinado tipo de prazer qualitativamente diferente de outro pode ser mais do que suficiente para escolher este prazer em relação a um outro prazer cuja quantidade seja imensa. O próprio utilitarismo de John Stuart Mill reconheceu a necessidade de distinguir os prazeres inferiores dos prazeres superiores - uma distinção qualitativa.

Além disso, um terceiro problema afeta a resposta dessa perspectiva ao conflito entre valores. É que o utilitarismo, ao estabelecer que os valores morais são aqueles que refletem o maior prazer, faz isso de forma coletivista: ou seja, considera que a ação moral é aquela que gera o maior prazer para todos os afetados pela ação, independentemente do resultado da ação para cada indivíduo afetado. Assim, uma ação ou um determinado valor estão justificados se gerarem um prazer imenso para todos, a despeito de terem violado diversos direitos fundamentais de um indivíduo particular. Se o sofrimento de um indivíduo for considerado pequeno diante dos benefícios obtidos por todos, a ação ou o valor estão justificados.

A quarta dificuldade do utilitarismo foi identificada especificamente por John Rawls: o utilitarismo não consegue diferenciar entre os vários indivíduos. Como o que importa é o valor líquido da soma de prazeres diminuído o sofrimento de alguns, o utilitarismo é incapaz de levar a sério a diferença entre as pessoas, tornando-se uma teoria opressora e incapaz de tratar todos como iguais (RAwLS, 2002, p. 24-30).

A terceira perspectiva monista aposta na existência de um princípio canônico capaz de ordenar os valores de modo a torná-los compatíveis uns com os outros. Essa forma de monismo supõe a existência de um princípio meta-axiológico capaz de ordenar os vários tipos de valores. Em caso de conflito, os valores melhor classificados no ranking estabelecido pelo princípio meta-axiológico assumem a condição de precedência em relação aos princípios pior classificados. Mas o que torna esse princípio de observância obrigatória para qualquer um que deseje resolver o conflito entre dois (ou mais) valores? Essa versão do monismo axiológico assume que é da própria natureza dos valores admitir este princípio canônico: podemos estabelecer um ranking entre todos os tipos de valores, e este princípio apenas expressa esta ordenação.

Essa perspectiva de abordagem acerca do conflito axiológico leva a duas possibilidades. Ou assume que cada valor tem uma característica inerente a si que o coloca em um necessário degrau do ranking, ou a classificação de cada valor no ranking decorre de alguma escala objetiva de valores (KeKEs, 1993, p. 74). A primeira alternativa se 
reduz ao monismo na versão summum bonum, ao reconhecer que é da própria natureza dos valores assumir determinada posição na ordem concreta de valores. A segunda alternativa, por sua vez, se reduz ao monismo em sua segunda versão, ao admitir que os valores podem ser traduzidos em uma medida comum em termos nos quais todos os valores podem ser expressos (a medida de "utilidade", na filosofia utilitarista). Essa alternativa ainda admite a possibilidade de realizar dois ou mais valores ao mesmo tempo, por um processo de ponderação a partir do qual um valor moral cede perante o outro, realizando a ambos proporcionalmente. Essa perspectiva está no cerne da teoria principiológica de Robert Alexy, como se verá a seguir.

\section{i.2 A teoria AXiológica dos princípios de Robert Alexy}

A distinção entre princípios e valores assume uma série de pressupostos filosóficos que precisam ser esclarecidos. Não é possível assumir, como Robert Alexy, a tese de que, quando o Tribunal Constitucional Federal alemão (Bundesverfassungsgericht) fundamenta suas decisões com base em valores, não assume nenhuma teoria filosófica mais sofisticada, mas apenas uma teoria "débil" dos valores, que seria aceita por qualquer teoria axiológica substantiva (AlEXY, 2002, p. 151). O fato é que o constitucionalista alemão pressupõe uma teoria filosófica substantiva (e não fraca ou débil) a respeito dos valores, cujos pressupostos precisam ser explicitados.

No conceito de constituição adotado por Alexy, os princípios constitucionais são compreendidos essencialmente como valores: ambos expressariam um sentido normativo que exige critérios de aplicação (AlEXY, 2002, p. 145). Estruturalmente, princípio e valor seriam idênticos, na medida em que ambos expressam critérios prima facie aplicáveis na avaliação de uma situação concreta (DANCY, p. 2003). Além disso, Alexy aponta que os princípios e valores estão intimamente vinculados, pois ambos admitem a possibilidade de colisão e ponderação, em virtude de haver princípios e valores que não podem ser realizados integralmente a um só tempo. Ademais, as duas categorias, segundo o autor, admitem o cumprimento gradual, ou seja, a realização de um valor ou princípio pode ser realizada de forma parcial. Assim, uma decisão concreta pode, a priori, realizar ambos os princípios/valores ao mesmo tempo, devendo um princípio/valor ceder proporcionalmente ao outro. Em virtude dessas semelhanças estruturais, Alexy afirma que os enunciados do Tribunal Constitucional Federal da Alemanha sobre valores podem ser reformulados em termos principiológicos, e vice-versa (AleXY, 2002, p. 139).

Apesar de reconhecer essas semelhanças, Alexy constata uma diferença importante entre as duas categorias. Seguindo a divisão estabelecida por Georg von Wright, Alexy afirma que os conceitos práticos se dividem em três grupos: conceitos antropológicos, deontológicos e axiológicos. Conceitos antropológicos são aqueles relativos ao homem - vontade, interesse, capacidade, necessidade, decisão e ação. Os conceitos deontológicos e axiológicos, por sua vez, se diferenciariam apenas a partir 
do seu conceito deôntico fundamental. O conceito deontológico fundamental é a idéia de "dever ser", ao passo que o conceito axiológico fundamental é a idéia de "bem".

Todavia, todo o esforço de Alexy para diferenciar valor e princípio se esvai, uma vez que, ao aplicar a mesma estrutura para valores e princípios, ambos se tornam indiferenciados, inclusive, naquilo que deveria diferenciá-los. Com efeito, se a única diferença entre princípio e valor está, respectivamente, naquilo que é "devido" e no que é "melhor", e se tanto valor quanto princípio assumem uma perspectiva normativa, nada há que impeça a indiferenciação entre ambos. Aliás, duas das mais influentes teorias éticas construídas ao longo dos últimos duzentos anos, o utilitarismo e a metafísica dos costumes kantiana, são baseadas na indiferenciação de valor e princípio. De um lado, esta é a estratégia utilitarista, cuja filosofia assume como dever a maximização daquilo que é bom. Do lado kantiano, por sua vez, bom é tudo aquilo que é devido, ou seja, tudo aquilo que é desejado em razão de ser racional, a partir do princípio ético de universalização, consubstanciado nas formulações do imperativo categórico. Nas duas formulações, portanto, o que é bom e o que é devido se confundem.

De qualquer maneira, tanto os conceitos deontológicos quanto os axiológicos, para Alexy, estabelecem normas (Alexy, 2002, p. 145). Assim, de acordo com o teórico alemão, norma é gênero subdividido em duas espécies: norma deontológica (que abrange regras e princípios) e norma axiológica (que se subdivide, por seu turno, em regras de valoração e valores, entendidos como critérios de valoração). A função das regras no contexto das normas deontológicas é análoga à das "regras de valoração" das normas axiológicas, e os princípios assumem no contexto deontológico o mesmo papel dos valores no contexto axiológico.

Embora também seja uma discussão relevante, a distinção entre regras e princípios é mais consensual, embora não de todo incontroversa. Segundo Ronald Dworkin, a distinção entre regras e princípios tem um caráter lógico e se dá a partir de dois fatores: em primeiro lugar, as regras são aplicáveis à maneira do tudo-ou-nada. Ou se obedece a uma regra, ou não. A regra é aplicável ou não: não há um meio-termo. A regra estipula o que deve ser feito numa determinada situação. Os princípios, de outro lado, não apresentam conseqüências jurídicas que se seguem automaticamente quando as condições são dadas - apontam apenas uma direção para a qual a decisão deve seguir, mas ainda assim necessita de uma decisão particular. Além disso, os princípios apresentam uma dimensão ausente nas regras - a dimensão da importância. Uma regra deve ser sempre aplicada quando o seu suporte fático for realizado, salvo alguma exceção ou razão de princípio, ao passo que os princípios, no caso concreto a ser discutido, podem assumir uma importância maior ou menor no contexto da argumentação (DWORKIN, 2002, p. 40-43).

Para Alexy, a função dos princípios é análoga aos critérios de valoração (valores). A única distinção decisiva entre princípios e valores está no caráter deontológico dos princípios e no caráter axiológico dos valores. Embora a afirmação seja óbvia, quer 
com isso apontar que os valores são relativos àquilo que é bom, ao passo que os princípios se relacionam com deveres (mandatos). Regras deontológicas são mandatos definitivos e os princípios são mandatos de otimização, ao passo que, no nível axiológico, a distinção ocorre entre regras de valoração, que devem ser ou não seguidas, não podendo ser objeto de ponderação, e valores, que podem ser objeto de ponderação. Nesses termos, a diferença fundamental entre princípios e valores está no fato de que "o que no modelo dos valores é prima facie o melhor é, no modelo dos princípios, prima facie devido; e o que no modelo dos valores é definitivamente o melhor é, no modelo dos princípios, definitivamente devido” (Alexy, 2002, p. 147).

A defesa de uma "teoria débil" dos valores, que não assumiria nenhum pressuposto filosófico forte, cai por terra justamente quando Alexy sustenta que os princípios são mandatos de otimização, sendo suscetíveis de ponderação, assim como os valores. Ao afirmar isso, Alexy se vale de uma teoria monista acerca da natureza dos valores, na medida em que aceita um critério último (ponderação ou otimização) capaz de resolver o problema do conflito entre princípios e valores. Esse pressuposto torna sua distinção entre princípios e valores tão fraca que, na verdade, passa a ver princípios e valores de maneira idêntica.

Essa caracterização dos princípios se torna particularmente importante no tratamento da problemática da colisão de princípios. Para Alexy, quando dois princípios entram em colisão, um deve ceder proporcionalmente ao outro: para decidir qual deve prevalecer, é necessário utilizar a lei de colisão, que é definida nos seguintes termos: em face de dois princípios $\left(\mathrm{P}_{1}\right.$ e $\left.\mathrm{P}_{2}\right)$ que colidem, é preciso dar preferência $(\mathbf{P})$ a um deles em face do outro, o que se dá tendo em vista as condições fáticas $\left(\mathrm{C}_{1}\right)$ presentes na situação concreta, que fornece elementos a serem abstraídos logicamente pelo julgador na busca por uma resposta (R) (Alexy, 2002, p. 157-158).

A estrutura da decisão judicial no caso de colisão entre princípios é a seguinte, no modelo de Alexy: $\left(\mathrm{P}_{1} \mathbf{P} \mathrm{P}_{2}\right) \mathrm{C}_{1}$ ? $\mathrm{R}$ (lê-se: o princípio 1 é preferível ao princípio 2 na condição 1 , que leva à resposta jurídica $\mathrm{R}$ ). Todavia, essa preferência não é total: ela deve estar de acordo com o princípio da máxima proporcionalidade, que é estruturado em torno de três máximas parciais: (i) o princípio da máxima proporcionalidade em sentido estrito, de acordo com o qual os princípios são mandatos de otimização em relação às possibilidades jurídicas; (ii) o princípio da adequação de meios a fins; e (iii) o princípio da necessidade, pelo qual a decisão deverá buscar o equilíbrio entre os princípios que seja menos lesivo às partes envolvidas. A primeira máxima aplica-se a circunstâncias jurídicas e as outras duas, a circunstâncias fáticas (Alexy, 2002, p. 111-113). No esquema de Alexy, o julgador deve abstrair a sua decisão do caso concreto a ser decidido a partir da lei de colisão, ou seja, deve levar as circunstâncias fáticas apresentadas no caso concreto $\left(\mathrm{C}_{1}\right)$ para o plano lógico e, a partir dessa perspectiva, verificar qual dos princípios deve ser preferido. 
Essa concepção acerca dos princípios, contudo, não se sustenta sequer do ponto de vista lógico. Deve-se lembrar, em primeiro lugar, de algo que os lógicos têm insistido desde Hume: princípios deontológicos não podem derivar sua validade ou sua aplicabilidade de condições fáticas, sob pena de incorrer na falácia naturalista. É precisamente por isso que Kelsen insiste tanto na distinção entre ser e dever ser: uma ordem jurídica não pode ser fundada em um fato do mundo (KELSEN, 2000, p. 221 222). Ao lançar condições fáticas para o plano lógico-deôntico no qual um juiz deverá decidir o caso concreto, Alexy viola essa condição lógica. Isso não significa dizer que o julgador não deve levar em consideração as circunstâncias fáticas do caso concreto que está decidindo, porém apenas que essas circunstâncias não assumem um caráter deontológico, mas apenas cognitivo. As circunstâncias fáticas apresentam o caso a ser decidido, sobre o qual o julgador deverá buscar, no ordenamento jurídico, os princípios e as regras que podem ser utilizados para justificar sua decisão sobre o caso. São essas circunstâncias que delimitam e orientam o julgador acerca das regras e dos princípios a serem empregados no processo argumentativo-justificatório da decisão. Entretanto, Alexy não diferencia circunstâncias fáticas de circunstâncias jurídico-lógicas, confundindo as duas.

Ao fazer isso, Alexy consegue, inclusive, levar as condições fáticas ao plano lógico que permite, abstratamente, definir um entendimento jurisprudencial em torno de princípios, com base no seguinte modelo: dadas as condições fáticas $\mathrm{C}_{1}, \mathrm{C}_{2}, \mathrm{C}_{3} \mathrm{e}$ $\mathrm{C}_{4}, \mathrm{P}_{1}$ deve ser preferido a $\mathrm{P}_{2}$. E mais: se as mesmas condições forem apresentadas em um caso posterior, a ordem de preferência deve ser mantida no novo caso concreto (Alexy, 2002, p. 93). Todavia, Alexy não responde se a ordem de preferência será alterada se, além de $\mathrm{C}_{1}, \mathrm{C}_{2}, \mathrm{C}_{3}$ e $\mathrm{C}_{4}$, for adicionada uma circunstância $\mathrm{C}_{5}$. Daí que seu modelo, mesmo se fosse válido, seria irrelevante, na medida em que sempre é possível adicionar novas circunstâncias fáticas não previstas na ordenação anterior, e tão relevantes quanto as anteriores. O princípio da proporcionalidade não ajuda em nada o processo interpretativo.

Ao estipular que o princípio da proporcionalidade regule a colisão entre princípios, Alexy adota uma teoria ética monista, pois prescreve um princípio canônico de ordenação dos princípios constitucionais. Assim, é simplesmente equivocada a sua tese de que a teoria adotada é apenas uma "teoria débil” acerca dos valores. É uma tese substantiva forte e, mais ainda, repleta de pressupostos filosóficos que precisam ser esclarecidos.

Em primeiro lugar, é preciso reconhecer que o princípio da proporcionalidade é meramente formal: não tem nenhum conteúdo, mas apenas procedimentos distintos inerentes a cada uma das três máximas parciais. Ou seja, Robert Alexy não assume uma teoria monista do summum bonum, já que não prescreve a adoção de nenhum valor em particular. Todavia, a tese monista de que existe um princípio canônico de ordenação dos valores pode assumir uma perspectiva que depende de uma escala objetiva de valores, como o utilitarismo. No utilitarismo, o princípio da maior felicidade de 
John Stuart Mill assume o papel de ordenador da escala objetiva de valores utilitarista, sendo responsável pela determinação de qual valor deve ter precedência em caso de conflito axiológico.

É precisamente esta a função do princípio da proporcionalidade na proposta de Robert Alexy. A primeira conseqüência da adoção de um metaprincípio para regular o conflito entre os princípios constitucionais é a adoção de uma escala objetiva de valores. E é precisamente o que acontece na teoria constitucional alemã, ao adotar o princípio da proporcionalidade: é o próprio Alexy que aponta a necessidade de uma "ordem hierárquica de valores”, capaz de resolver as colisões de direitos fundamentais:

[...] É possível dizer, em geral, que não é possível uma fixar uma ordem de valores ou princípios que fixe a decisão jusfundamental em todos os casos de uma maneira intersubjetivamente obrigatória. Contudo, a impossibilidade de uma ordem "dura" deste tipo não diz nada acerca da possibilidade de ordens mais "brandas" e, desde logo, nada contra o conceito de ponderação. Ordens brandas podem surgir de duas maneiras: (1) através de preferências prima facie a favor de determinados valores ou princípios e (2) através de uma rede de decisões concretas de preferências. Uma ordem branda dos valores de direitos fundamentais relevantes é obtida quando, por exemplo, se supõe uma carga de argumentação em benefício da liberdade individual ou da igualdade ou em benefício de bens coletivos. Uma ordem branda através de uma rede de decisões concretas de preferência surgiu como conseqüência da jurisprudência do Tribunal Constitucional Federal. Ambos estão estreitamente vinculados com o conceito de ponderação (AlEXY, 2002, p. 157).

O princípio da proporcionalidade de Alexy e a sua filosofia dos valores implícita são tributários da tradição constitucional alemã, que busca na unidade decorrente do compartilhamento de valores a única saída possível para lidar com os conflitos originados de uma vida social marcada pelo fato de que as pessoas sustentam diferentes concepções de mundo e, portanto, assumem diferentes valores. Nesse contexto, é necessário refletir a respeito da legitimidade da perspectiva segundo a qual os princípios constitucionais são valores.

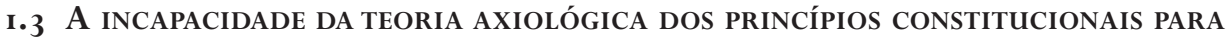 LIDAR COM O FATO DO PLURALISMO}

A questão da natureza dos princípios constitucionais se torna ainda mais importante no contexto contemporâneo em que não há consenso sobre os valores relevantes na nossa vida social. As sociedades democráticas contemporâneas são pluralistas e simplesmente não existem valores substantivos compartilhados por todos e capazes de guiar nossa vida tanto em uma perspectiva individual quanto coletiva. 
A incapacidade de lidar com essa questão é o principal problema de uma teoria acerca dos princípios constitucionais que os caracterize como valores. Valores são preferências individuais ou intersubjetivamente compartilhadas entre os membros de uma comunidade ou cultura (SPATES, 1983, p. 27-49). Mas, se é assim, é simplesmente injustificável tratar os princípios constitucionais a partir de uma teoria axiológica, tendo em vista que isso exigiria um compromisso ético dos cidadãos com determinados valores que, contudo, podem não ser adotados por todos. Se é assim, escolher um valor ou um critério de decisão apto a hierarquizar quais são os valores mais importantes numa determinada sociedade é uma atitude arbitrária. Qualquer valor ou conjunto de valores escolhido pode ser incompatível com os valores de um ou mais indivíduos, excluindo-os da oportunidade de uma convivência livre e igual com os outros membros da sociedade.

O pluralismo pode ser assumido ainda de pelo menos dois pontos de vista distintos: (i) da perspectiva das diferentes concepções de bem que podem ser defendidas em uma sociedade democrática; e (ii) do modo pelo qual se compreende a estrutura lógica dos princípios, na medida em que se assume a igual validade de cada princípio, sem ordenação lexical nenhuma entre eles. Estas duas formas de pluralismo correspondem a dois níveis lógicos distintos: a primeira concepção, a que chamarei, com Rawls, de pluralidade de doutrinas abrangentes (RAWLS, 2000, p. 102110), se realiza sociologicamente e, portanto, no plano lógico do ser; a segunda concepção, por outro lado, ocorre no plano lógico do dever ser, e a denominarei de pluralismo deontológico estrutural. O termo "estrutural" tem a função de diferenciar conceitualmente essa modalidade de pluralismo de um pluralismo deontológico simples, passível de ser defendido como teoria monista que hierarquiza diversos princípios e estabelece critérios claros de ordenação.

Uma questão surge, a partir da distinção do pluralismo nessas duas vertentes, uma empírica e uma deontológica. Elas estão interligadas? E, se sim, de que modo? A resposta a essas questões importa para verificar se uma teoria que concebe a constituição como uma ordem concreta de valores e, portanto, assume o pluralismo deontológico simples é capaz de estruturar uma sociedade estável composta por cidadãos que se vêem como livres e iguais, apesar de defenderem uma pluralidade de doutrinas inconciliáveis.

Uma sociedade pluralista leva a sério a possibilidade de que as questões políticas e jurídicas sejam objeto de discussão pública, na medida em que é composta por várias comunidades que adotam uma pluralidade de doutrinas abrangentes religiosas, filosóficas e políticas. Com isso, cada comunidade que compõe uma sociedade democrática pluralista adota critérios distintos para o próprio exercício da discussão pública e, até por uma consistência interna de seu sistema de crenças, ou (i) percebe que os princípios constitucionais devem ser hierarquizados de um modo distinto, de comunidade para comunidade; ou, (ii) se determinadas pessoas conseguem realizar 
uma distinção absoluta entre a doutrina abrangente que defende e a sua própria concepção política, podem assumir uma postura na qual não adotam nenhuma hierarquia principiológica concreta, mas o pluralismo deontológico estrutural, e que esta é uma questão a ser debatida em cada caso concreto.

É por isso que a proposta de uma constituição como ordem concreta de valores, que assume o pluralismo deontológico simples, é incompatível com uma sociedade pluralista que reconhece seriamente seus membros como cidadãos livres e iguais. De imediato, se uma teoria assume uma hierarquia entre princípios a partir de algum critério, não pode levar a sério o debate público com outras teorias que admitem hierarquias deontológicas distintas ou mesmo que pensam que o debate não deve ser levado em virtude de uma hierarquia, mas em razão dos melhores argumentos postos a favor de diferentes considerações (não necessariamente hierárquicas).

O risco imediato da perspectiva axiológica está na própria interrupção do debate em torno de uma estrutura principiológica prévia, mas os riscos se potencializam ainda mais quando não se distinguem efetivamente princípios e valores.

\section{A CONSTituiçÃo deOnTOlógiCA: PRincíPIOS, NÃO VAlORES}

O problema do desacordo moral, i.e., a situação na qual os cidadãos não concordam entre si a respeito dos valores fundamentais que devem reger a vida social, tem sido uma preocupação teórica de alguns teóricos que recuperaram a concepção estrutural do argumento contratualista clássico com a finalidade de elucidar os pressupostos teóricos inerentes à estrutura constitucional das sociedades pluralistas. Isso não significa dizer que os pressupostos metafísicos do contratualismo foram recuperados: é inviável, hoje, defender a legitimidade do direito ou a estrutura da argumentação jurídica a partir de idéias como "estado de natureza" ou "contrato social”. Mas o contratualismo clássico deixou como legado a estrutura da argumentação a respeito dos pressupostos que precisamos assumir numa cultura democrática. É o que John Rawls chama de "construtivismo kantiano": a tarefa da filosofia jurídico-política não é "fundamentar" a nossa ordem política, como acreditavam os contratualistas, mas elucidar os pressupostos teóricos que já estão implícitos nas nossas práticas e instituições e que podem justificá-las como resultado de um procedimento justo, que trata as pessoas imparcialmente (RAWLS, 2002, p. 135).

Outros teóricos contemporâneos que assumem um construtivismo análogo ao de Rawls, embora partam de uma perspectiva epistemológica distinta, são Jürgen Habermas e Ronald Dworkin. Habermas, por exemplo, busca os pressupostos contrafáticos de sua teoria na filosofia da linguagem, a partir das condições ideais de fala, situação ideal pressuposta nas sociedades democráticas em que cada pessoa teria o direito de se manifestar a respeito de qualquer tema e de colocar qualquer pauta que desejasse. Nessa situação, todos seriam livres e iguais, na medida em que teriam 
o mesmo direito de intervir nas discussões públicas, sendo livres para participar da discussão sem sofrerem restrições substantivas quanto ao conteúdo do discurso, salvo restrições procedimentais com o objetivo de assegurar a todos os outros participantes do diálogo um direito igual de participação (HABERMAS, 2003, p. 154-168). O construtivismo de Dworkin, de outro lado, está implícito em sua teoria da interpretação judicial, na medida em que concebe o direito como um romance em cadeia. Ao decidir um caso concreto, o julgador deve assumir a perspectiva de um julgador ideal (o juiz Hércules) que seria capaz de reconstruir à melhor luz toda a história constitucional e de identificar para o caso concreto os princípios constitucionais que melhor justificariam uma decisão capaz de fazer justiça à pretensão de todas as partes. Isso não significa dizer que Dworkin defenda uma ditadura da história institucional sobre os juízes, mas que essa história restringe suas possibilidades de decisão, embora, a qualquer momento, possa ser reconstruída pelo intérprete com o objetivo de decidir o caso da forma mais justa possível (DWORKIN, 1999, p. 213-132; 425-476).

Assim, embora os três autores partam de perspectivas teóricas bastante distintas, todos admitem o caráter contrafático e universal da legitimidade do poder jurídico. E é justamente por isso que conseguem justificar uma teoria acerca dos princípios constitucionais que não os reduz a valores. Para Rawls, Habermas e Dworkin, os princípios constitucionais são distintos logicamente dos valores em virtude da "prioridade do justo sobre o bem" (RAWLS, 2000, p. 221-261; HABERMAS, 2004, p. 310-318; Dworkin, 2002, p. 371-408). Com isso, os três rompem com a perspectiva de que os princípios constitucionais incorporam valores morais compartilhados culturalmente. Assumir isso seria justamente voltar a uma perspectiva pré-moderna, em que se reconhece o caráter inevitavelmente autoritário e excludente do direito, que se torna incapaz de lidar com uma sociedade complexa e plural, cujos cidadãos simplesmente não entram em acordo a respeito dos valores que devem guiar sua vida comum.

A prioridade do justo sobre o bem se sustenta sobre dois patamares lógicos diferentes: um, relativo aos princípios de justiça que devem ser aceitáveis por todos para regular a vida social; e outro, relativos aos valores (ou, em termos rawlsianos, às concepções de bem) defendidos pelos indivíduos e pelas comunidades que fazem parte de qualquer sociedade pluralista. Ao fazer essa distinção lógica, torna-se necessário lidar com três tipos de problemas: em primeiro lugar, essa distinção assume uma teoria sobre os valores que, portanto, precisa ser esclarecida. O segundo problema é o estabelecimento de uma origem imparcial e independente (free-standing) de qualquer contexto moral específico, a partir da qual se torna possível postular uma avaliação justa das várias pretensões de validade moral oriunda dos discursos éticos que dialogam no interior de uma sociedade democrática. Em terceiro lugar, é preciso assumir uma íntima ligação do direito com a moral que garanta a estabilidade do direito numa 
determinada sociedade, sem estabelecer uma relação de dependência do direito no tocante a valores morais específicos.

Ao distinguir questões relativas à justiça das questões relacionadas aos valores, a teoria liberal igualitarista assume uma determinada concepção acerca dos valores: o pluralismo. Essa teoria assume que os valores têm algumas características lógicas que tornam impossível aceitar uma teoria monista. Como visto, a primeira versão do monismo axiológico aceita que um valor ou um conjunto de valores é mais importante que os outros e, portanto, em caso de conflito, deve prevalecer sobre os outros valores. A segunda versão aceita a existência de uma medida comum que permite avaliar o conjunto de valores que é mais valioso e que, portanto, pode ser utilizada para criar uma tabela concreta dos valores. E a terceira versão aceita que é possível desenvolver um princípio meta-axiológico capaz de ordenar de forma adequada os valores, de modo a alcançar o arranjo mais proveitoso possível.

A perspectiva pluralista rejeita essas três versões do monismo. Em primeiro lugar, aceita que todos os valores estão em pé de igualdade e que, portanto, não existe um valor superior que seja superior a todos os outros. Além disso, também não existe uma medida comum capaz de traduzir em seus termos todos os valores, pois estes são qualitativamente diferentes e, portanto, não compartilham nada que seja redutível a uma medida comum. O que deve valer mais? O amor ou a sabedoria? A paz ou a verdade? O pluralismo nega que exista uma prioridade dos vários valores in abstracto. Em terceiro lugar, de acordo com o pluralismo, não existe critério superior como o princípio da proporcionalidade ou o princípio da utilidade capaz de hierarquizar os diferentes valores de modo a lidar com o conflito axiológico. Não existe um critério superior justamente porque qualquer critério só seria justificável axiologicamente: um utilitarista poderia dizer que "prefere" o princípio da utilidade como critério de resolução dos conflitos axiológicos, ao passo que Alexy poderia dizer que "prefere" o princípio da proporcionalidade, mas escolher entre um critério ou outro necessitaria da própria aceitação apriorística daquele princípio, ou seja, dependeria, em última instância, dos valores que o agente moral já aceita. Assumir essa postura, principalmente no contexto de tomada de uma decisão judicial, na qual o juiz precisa decidir qual das pretensões morais é justificada à luz dos princípios jurídicos, implica escolher arbitrariamente entre os princípios em conflito a partir das preferências pessoais do juiz. Mas isso é simplesmente autorizar a exclusão de qualquer possibilidade de manifestação de valores diferentes daqueles aceitos pelo sistema jurídico e, portanto, implica assumir uma postura autoritária perante o direito.

Isso nos leva ao segundo problema que precisa ser esclarecido: a teoria pluralista precisa do estabelecimento de uma origem imparcial e independente (free-standing) de qualquer contexto moral específico, a partir da qual se torna possível postular uma avaliação justa das várias pretensões de validade moral oriunda dos discursos éticos que dialogam no interior de uma sociedade democrática. Isso só é 
possível quando se distinguem os domínios de discussão acerca dos princípios constitucionais e acerca das questões de valor. A proposta de John Rawls, endossada explicitamente por Jürgen Habermas (2003), parte da idéia de que os conflitos morais devem ser resolvidos a partir de princípios constitucionais aceitáveis por todos os cidadãos.

A aceitação destes princípios decorre do surgimento de um consenso em torno de razões legítimas às quais os cidadãos podem recorrer para decidir determinados conflitos de valor e que, portanto, constituem-se em normas cujo cumprimento é obrigatório em virtude de serem aceitas por todos. Além disso, a dimensão deontológica dos princípios não aceita a categoria da solução gradual, como a categoria dos valores admite. Valores podem ser realizados parcialmente a partir de um balanceamento: princípios, não. Os princípios, caso pretendam ter validade universal, devem estar inseridos num sistema coerente, que admite apenas uma codificação binária: ou o princípio é válido, ou inválido. Princípios não podem colidir, mas apenas ser afastados, no caso específico de aplicação, diante de considerações e razões deduzidas a partir de outros princípios (HABERMAS, 1997, p. 317-318). É apenas no caso concreto que um princípio prevalece perante o outro, dadas as razões que são apresentadas em defesa de cada um dos princípios para aquele caso específico. É simplesmente impossível estabelecer uma hierarquia concreta de valores a partir da jurisprudência da corte constitucional, como pretende Alexy, justamente porque o estabelecimento dessa hierarquia pressuporia a imposição de uma certa ordem de valores em detrimento dos valores que são efetivamente defendidos pelos cidadãos, e isso seria opressor contra aqueles que defendem valores diferentes. É justamente por isso que princípios e valores devem ser mantidos como categorias lógicas distintas, com a prevalência dos princípios, na medida em que são razões aceitáveis por todos, ao contrário dos valores, que só são aceitos por alguns. É por isso que os princípios devem ser entendidos como uma proteção contra os valores da maioria: os direitos são trunfos a serem utilizados na defesa dos cidadãos contra argumentos fundados em valores coletivos (DWORKIN, 2002, p. XV).

Essa consideração leva ao terceiro problema. É quase um truísmo dizer que todo direito se manifesta numa sociedade concreta e que, em certa medida, reflete os valores morais compartilhados intersubjetivamente. Nesse contexto, é importante diferenciar as questões éticas das questões morais: questões éticas são resolvidas a partir dos valores compartilhados pelo indivíduo com sua comunidade, ao assumir uma determinada forma de vida que constitui "o sistema de referência para a fundamentação de regulamentações que valem como expressão de um auto-entendimento coletivo consciente" (HABERmAs, 1997, p. 143). As questões relativas aos valores se subordinam ao domínio da ética, que estabelece uma perspectiva acerca daqueles valores cuja realização é necessária para ter uma vida boa. O sistema de referência das questões morais, de outro lado, não é o conjunto de valores compartilhados por 
uma mera comunidade, mas a busca de um sistema de regulação universalizável, que pode ser aceito, em princípio, por todos.

É importante não confundir essas duas ordens de questões. Quando se diz que o direito manifesta os valores de uma sociedade concreta, precisamos deixar de lado a idéia de que a ética é o fundamento último do direito. Se fosse assim, o pluralismo corrente nas sociedades contemporâneas seria percebido como um mal, e não como uma característica inerente e positiva das democracias constitucionais. A idéia de que o direito deve sua legitimidade a valores éticos precisa ser abandonada, na medida em que depende de uma fundamentação metafísica abandonada historicamente, fundada na subordinação do direito positivo perante o direito natural.

Essa relação de dependência precisa ser abandonada, o que não significa dizer que não existe uma ligação íntima entre direito e moral. De acordo com Habermas, essa relação é de complementaridade (HABERMAS, 1997, p. 142). O direito não se subordina à moral, tampouco a moral é subordinada ao direito. Uma ordem jurídica não pode contrariar princípios morais, mas aceitar esta tese não implica aceitar uma hierarquia entre a ordem jurídica e a ordem moral. O direito, ao contrário da moral, é obrigatório institucionalmente, ao passo em que a moral é apenas um sistema simbólico que, contudo, exerce uma importante função reguladora da legitimidade dos discursos jurídicos, ao promover uma perspectiva universal a partir da qual se torna possível avaliar se o direito positivo está conferindo um igual tratamento às diferentes perspectivas éticas, ou se está sendo utilizado de modo a promover determinados valores em detrimento de outros. Apesar de regular a legitimidade do direito, a moral não assume uma hierarquia superior diante do direito. O direito também exerce influências sobre a moral, tornando as suas exigências institucionalizáveis juridicamente.

Além disso, a relação de complementaridade entre direito e moral garante a própria estabilidade do direito. Se os princípios constitucionais institucionalizados por meio do direito não se refletissem nas crenças morais e éticas dos cidadãos, o sistema jurídico seria absolutamente instável na medida em que não conseguiria obter o consenso social necessário para assegurar sua legitimidade. Para que isso aconteça, é preciso que todos os cidadãos incorporem os princípios constitucionais como valores morais componentes de sua doutrina ética particular, no que Habermas denominou de "patriotismo constitucional" e Rawls, de "consenso sobreposto". Assim, do ponto de vista de cada doutrina ética, os princípios constitucionais seriam incorporados como valores imanentes à doutrina, ao passo que, de uma perspectiva institucional, tais princípios mantêm sua independência estrutural perante qualquer sistema de valores. É por isso que confundir princípios e valores é um risco sempre presente e extremamente sério, pois implica privilegiar uma determinada perspectiva ética em detrimento de todas as outras. É justamente o erro que não se pode cometer no contexto contemporâneo de sociedades extremamente plurais em que 
há grupos radicais que pretendem impor seus valores éticos a qualquer custo, independentemente de qualquer consideração a respeito dos direitos humanos.

A distinção entre valores e princípios está implícita no tratamento dado por Rawls à ordenação lexical dos seus famosos dois princípios de justiça, em que se confere prioridade aos direitos e liberdades fundamentais em relação a considerações de eficiência socioeconômica, mas não prescreve prioridade interna nenhuma entre os direitos e liberdades garantidos em uma constituição (RAWLs, 2003, p. 65). O filósofo de Harvard reconhece a impossibilidade de aplicação de juízos de eficiência conseqüencialista no processo de interpretação dos direitos e garantias fundamentais, princípios básicos do ordenamento constitucional. Rawls reconhece, portanto, o pluralismo deontológico estrutural, e não permite a adoção de critérios de hierarquização principiológica.

De outro lado, o liberalismo político de Rawls assume duas distinções que denotam o seu compromisso com uma concepção deontológica de princípios, que logicamente se estruturam de modo diverso dos valores. A primeira é a distinção entre conceito e concepção, também adotada por Ronald Dworkin (DWORKIN, 2002, p. 210-214; RAWLS, 2002, p. 5-6), que pode ser reconstruída nesses termos:

Quando recorro ao conceito de justiça, recorro ao significado do conceito de justiça (I appeal to what fairness mean), e não atribuo nenhuma importância especial a meus pontos de vista sobre a questão. Quando formulo uma concepção de justiça, defino um sentido para o conceito de justiça (I lay down what I mean by fairness), e por isso meu ponto de vista está no cerne do problema. Quando apelo à justiça, coloco uma questão moral; quando formulo minha concepção de justiça, tento respondê-la (Dworkin, 2002, p. 213).

A segunda distinção é a separação entre concepções políticas e doutrinas abrangentes, que Rawls formula nos seguintes termos: uma doutrina abrangente é qualquer teoria acerca de posições filosóficas, morais e religiosas que não possa ser necessariamente endossada por uma sociedade cujos membros se vêem como livres e iguais. De outro lado, uma concepção política se refere ao modo pelo qual devemos organizar uma sociedade cujos membros são livres e iguais. De pronto, uma concepção política não pode recorrer apenas aos valores defendidos por uma doutrina abrangente, visto que excluiria os defensores de outras doutrinas abrangentes e os trataria como desiguais. Todavia, as doutrinas abrangentes razoáveis reconhecem a plausibilidade das concepções políticas no seio de sua própria doutrina abrangente, por razões próprias, embora reconheça que as concepções políticas podem ser defendidas recorrendo apenas ao ideal de razão pública, que prescreve o recurso apenas aos princípios políticos que poderiam ser aceito por todos.

Essas duas distinções estão associadas à diferenciação entre valor e princípio, e é deixada de lado por Alexy. Um princípio é um conceito, ou seja, do ponto de vista 
estrutural, é abstrato: sua realização se dá no processo de fundamentação de uma decisão razoável. Um valor, por sua vez, reflete uma concepção a respeito de várias classes de coisas, entre elas, os princípios. ${ }^{3}$ Ocorre que uma concepção que compreenda a constituição como uma ordem concreta de valores se compromete necessariamente com a interpretação de princípios a partir dos valores aceitos por uma determinada doutrina abrangente (GALSTON, 2002, p. 65-81).

Isso traz riscos inaceitáveis para uma democracia constitucional que pretenda lidar com o pluralismo. A doutrina abrangente da teoria de Alexy, por exemplo, torna obrigatório à comunidade jurídica a aceitação de uma ordenação de princípios baseada na máxima de proporcionalidade, o que exclui de imediato a possibilidade do dissenso acerca da natureza da interpretação principiológica.

Enquanto aceita como concepção abrangente, a tese de Alexy pode ser entendida apenas como mais uma das concepções políticas envolvidas no debate público acerca do modo pelo qual a constituição deve ser interpretada. Todavia, se esta concepção for aceita como concepção defendida pelo tribunal constitucional, que deve justificar suas posições a partir apenas do ideal da razão pública, se torna um risco para o pluralismo, na medida em que qualquer outra concepção política também pautada pelo ideal de razão pública é excluída aprioristicamente do debate (RAwls, 2000, p. 262-298). Nesse sentido, a concepção de Alexy não se apresenta como razoável, dado que uma instância jurídica que adote a idéia de princípios constitucionais como mandatos de otimização apresenta como conceito aquilo que, na verdade, é uma concepção acerca do modo pelo qual devemos interpretar a constituição. O risco primordial da leitura da constituição como ordem concreta de valores é a imposição dos valores morais de uma doutrina abrangente a toda a sociedade, excluindo a possibilidade do diálogo racional acerca dos princípios constitucionais que regem uma sociedade marcada pelo fato do pluralismo razoável.

Uma constituição que pretenda lidar com o pluralismo de concepções morais que caracteriza as sociedades democráticas deve apresentar alguns traços básicos: (i) deve limitar em grau mínimo as possibilidades de desenvolvimento de concepções do bem, por meio da delegação de direitos e garantias básicas; (ii) deve apresentar uma estrutura pública que parta de concepções políticas acerca dos princípios fundamentais da sociedade, e não (apenas) de concepções valorativas derivadas de doutrinas abrangentes; (iii) deve delinear instituições articuladas em cargos e posições acessíveis a todos e capazes de articular, por meio de concepções políticas, respostas justificadas para as demandas postas ao poder público; e (iv) deve assegurar condições mínimas do exercício das liberdades e dos direitos garantidos em (i).

A teoria axiológica dos princípios não fornece, pelos motivos já expostos, uma concepção adequada da justificação pública, isto é, uma concepção a respeito do modo pelo qual as instituições são legitimadas e as discussões devem ser travadas nos fóruns 
públicos. Uma concepção de justificação pública não pode recorrer a valores morais aceitos apenas por alguns dos cidadãos, mas a princípios que todos os cidadãos poderiam razoavelmente endossar (GAUS, 1996).

Que elementos esta teoria da constituição precisa assumir? Em primeiro lugar, para evitar os riscos metafísicos das teorias jusnaturalistas, é necessário reconhecer uma conseqüência teórica da co-originalidade das autonomias pública e privada: a co-originalidade entre homem e sociedade. Ao contrário dos republicanos e dos comunitaristas, que postulam a preexistência (e superioridade) da sociedade ao homem, e ao contrário dos liberalismos clássicos, que afirmavam a preexistência do homem em relação à sociedade, é necessário reconhecer, com o liberalismo político contemporâneo e a teoria crítico-deliberativa de Habermas, que as duas instâncias são interdependentes. Sendo assim, não é mais possível recorrer a direitos jusnaturalistas, transcendentais à política, como dados empíricos de onde nossas considerações devem partir. Mas também não podemos delegar tudo à política, sob pena de corrermos o risco de sucumbir ao autoritarismo coletivista.

Assim, como segundo elemento dessa teoria dos princípios, é necessário recorrer à história institucional de uma sociedade concreta e verificar os princípios que se consagraram institucionalmente, uma vez que, ao longo da história, foram considerados vitoriosamente justificados ou, pelo menos, não conseguiram ser derrotados por outros argumentos melhores (GAUS, 1996). Os princípios constitucionais devem ser interpretados coerentemente tanto com a prática institucional quanto com as idealizações contrafactuais acerca dos princípios que poderiam ser aceitos para regular uma sociedade cujos cidadãos são livres e iguais. ${ }^{4}$

Como articular, então, a relação entre o passado institucional e nossas idealizações contrafactuais? Uma resposta a essa questão compatível com o ideal de justificação pública supramencionado parte da idéia de coerência e se encontra, de modo geral, nas perspectivas teóricas de Dworkin (integridade), Günther (coerência) e Rawls (equilíbrio reflexivo). Já em 1971, na primeira formulação da teoria da justiça como eqüidade (fairness), Rawls afirmou a necessidade de coerência entre nossas intuições morais, carregadas de informações relevantes sobre nosso passado institucional, e os princípios abstratos. O método rawlsiano do equilíbrio reflexivo procede em três estágios, no processo de formulação de juízos morais: em primeiro lugar, é necessário identificar um conjunto de juízos refletidos acerca da justiça no caso concreto, em condições de informação suficiente para produzir julgamentos relevantes e adequados. Em segundo lugar, procede-se à busca de princípios que poderiam fundamentar os juízos escolhidos no primeiro estágio. No terceiro estágio, é necessário avaliar se os princípios e os juízos são reciprocamente compatíveis e, se não o forem, é imperativa a decisão de reformular os princípios ou os juízos refletidos, de modo a compatibilizá-los mutuamente (SCANLON, 2002, p. 140-141). Nas palavras de Günther: 
Com freqüência emitimos um juízo intuitivo com referência a uma situação concreta. O conjunto imprevisível de situações possíveis e suas características diferentes correspondentes modificam contunuamente a significação dos princípios sobre os quais apoiamos nossas reflexões morais intuitivas. Por essa razão entendemos que o juízo moral particular que consideramos correto em uma situação não resulta compatível à primeira vista com princípios que, em outras circunstâncias, aceitaríamos como válidos. Sem dúvida isto é aplicável a todos os casos nos quais a confrotação com um novo caso força a revisão recíproca de juízos e princípios, isto é, em um caso no qual emitimos um novo juízo. Mas se a novidade do caso produzida pela mutável constelação de situações põe o equilíbrio reflexivo novamente em movimento, é possível especificar o princípio de coerência no próprio caso. (GÜNTHER, 1995, p. 277).

Klaus Günther reconhece o potencial justificatório de uma teoria da interpretação que busca ver o conjunto de princípios disponíveis de forma coerente e confere a Rawls a originalidade desta idéia, comparando-a com a noção de integridade proposta por Dworkin.

No fulcro das instituições capazes de articular-se com o ideal de pluralismo, é necessário firmar uma distinção, já clássica no pensamento liberal, e inerente ao próprio entendimento da co-originalidade entre autonomias pública e privada, entre razão pública e razão não-pública. No fundo, esta também é uma decorrência da distinção entre valores, associados à razão não-pública (que é a razão particular das concepções defendidas em doutrinas abrangentes), e princípios, associados à razão pública. Dessa distinção, alguns grupos de questões se associam a cada classe de razão: as relativas a concepções de bem, doutrinas filosóficas e morais, que são inconclusivas e não podem ser impostas coercitivamente, em nome do pluralismo, devem ser propostas no âmbito da razão não-pública.

A tradição liberal contemporânea ligada a Rawls e a Dworkin entende que apenas as questões relativas às concepções políticas que partam dos princípios publicamente justificados podem ser propostas no âmbito da razão pública. Essas questões diriam respeito à justiça (igual consideração de todos) e ao respeito aos procedimentos (fairness), articuladas por meio do equilíbrio reflexivo, no caso de Rawls, e da integridade (integrity), no caso de Dworkin (RAwls, 2000, p. 277-281; DwOrkin, 2002). Além disso, a justiça é institucionalizada por meio dos direitos e das políticas, com a supremacia dos primeiros sobre as segundas, no sentido de que uma política não pode violar direitos, entendidos como trunfos individuais. Nas palavras de Ronald Beiner:

Ronald Dworkin deixou clara a natureza desse preço com sua famosa imagem dos "direitos como trunfos". Assim como no domínio dos direitos 
individuais, alguém tem um direito à liberdade de expressão se as pretensões à expressão livre superam qualquer outro bem social que esteja em conflito com o exercício desse direito, também no domínio dos direitos coletivos, um grupo tem um "direito" à autodeterminação nacional se a pretensão à autodeterminação supera outros bens sociais que possam estar em conflito com o exercício desse direito (BEINER, 2003, 152).

Com isso, uma teoria constitucional baseada na apresentação de razões fundadas em princípios não-hierarquizados, a serem interpretados com base na coerência entre suas intuições morais e as normas principiológicas em um processo de equilíbrio reflexivo, e não em valores ponderados, é compatível com a idéia de direitos individuais. Uma constituição compreendida como ordem concreta e hierarquizada de valores é incompatível com o pluralismo deontológico estrutural. Além disso, ante o compromisso com a máxima da proporcionalidade, a teoria de Alexy não pode ser seriamente compatibilizada com a própria idéia de direitos individuais, visto que, em face de sua relação com a teoria utilitarista de regras, não pode distinguir entre direitos, princípios e políticas, uma vez que opera por meio da lógica da eficiência. Assim, essa teoria não é capaz de impedir a violação de direitos por meio de políticas, pois seu critério ordenador, a máxima de proporcionalidade, não reconhece a prioridade lexical que confere supremacia dos direitos em relação às políticas públicas, nem a prioridade dos princípios sobre os valores.

: ARTIGO APROVADO (12/9/2008) : RECEBIDO EM 04/07/2008

NOTAS

1 Mestre em Direito, Estado e Constituição e Especialista em Filosofia (ambos pela Universidade de Brasília) e membro do Grupo de Trabalho em Mediação, Negociação e Arbitragem e do Grupo de Pesquisa Pensamento Social (plataforma Lattes/CNPq).

2 É imprescindível ressaltar que o liberalismo contemporâneo se divide fundamentalmente entre o liberalismo político e o econômico. Essa distinção é importante porque permite diferenciar estruturalmente o liberalismo clássico, em que as duas vertentes se confundiam, e os neoliberalismos, desenvolvidos a partir da década de 1950. A corrente neoliberal se estrutura a partir dessas duas vertentes, o liberalismo político, que valoriza as instituições democráticas e a teoria dos direitos liberais, e o liberalismo econômico, que privilegia uma economicização do mundo político. Essa última vertente, baseada primordialmente nos trabalhos de Friedmann e Hayek, é o marco teórico do chamado movimento de globalização neoliberal e do consenso de Washington. Essa separação é visível no mundo político atual: o liberalismo político de Rawls, por exemplo, tem sido adotado pela esquerda, com a criação de instrumentos políticos 
com a finalidade de diminuir diferenças socioeconômicas (o princípio da diferença, de Rawls), e um capitalismo desenfreado, embora defendido pelos neoliberais econômicos, é rejeitado tanto pelo liberalismo político quanto pela esquerda. Esse traço é visível na defesa de ações afirmativas por Ronald Dworkin, cuja teoria da justiça é bastante próxima da defendida no programa de justiça como equidade de John Rawls. A respeito das diversas concepções do liberalismo contemporâneo, cf. Gaus, 2003.

3 O próprio Alexy reconhece esse caráter dos valores: "Muchas cosas diferentes pueden ser objeto de valoración. Pueden valorarse, por ejemplo, objetos naturales, artefactos, pensamientos, acontecimientos, acciones y situaciones" (Alexy, 2002, p. 143).

4 A respeito da importância das idealizações contrafactuais, veja-se a seguinte passagem: "Para a construção e reconstrução lidarem com as antinomias entre fato e norma e entre o real e o ideal há uma longa e venerável linhagem que inclui as teorias reconstrutivas de Hobbes, Rousseau, Kant, Rawls e Habermas, dentre outros. A teoria reconstrutiva foi criativamente aplicada na interpretação jurídico-constitucional por Ronald Dworkin. No entanto, uma vez que os ideais imagináveis são de uma variedade infinita, a chave para se avaliar adequadamente o mérito de uma determinada teoria reconstrutiva reside em se determinar a lógica e o grau de persuasão com que essa teoria compara o real e o ideal, ou o factual e a imaginação contrafactual. [...] Precisamente porque o ideal é concebido como uma suplementação do real, a teoria reconstrutiva volta-se para a fundamentação de uma justificativa normativa para o status quo. Por outro lado, quando o ideal é considerado em contradição com o real, a teoria reconstrutiva é capaz de fornecer uma crítica das instituições vigentes" (Rosenfeld, 2003, p. 43-44). A idealidade é uma característica ínsita a vários filósofos contemporâneos: Dworkin (a metáfora do juiz Hércules); Rawls (o construtivismo kantiano); e Habermas (as condições ideais do discurso).

\section{REFERÊNCIAS BIBLIOGRÁFICAS}

ALEXY, Robert. Teoría de los derechos fundamentales. Madrid: Centro de Estudios Políticos y Constitucionales, 2002. (Colección El derecho y la justicia.)

BEINER, Ronald. Liberalism, Nationalism, Citizenship. Vancouver: UBC Press, 2003.

BELLAMY, Richard. Liberalism and pluralism: towards a politics of compromise. London: Routledge, 1999.

BRUGGER, Winfried. Communitarianism as the social and legal theory behind the German constitution. International Journal of Constitutional Law, v. 2, n. 3, 2004.

CASTRO, Marcus Faro de. Beyond liberalism and its critics: an essay in constitutional theory. Dalhouse Law Journal, v. 14, n. 3, May 1992.

DANCY, Jonathan. An ethic of prima facie duties. In: SINGER, Peter (Org.). A companion to ethics. Oxford: Blackwell, 1993.

DWORKIN, Ronald. O império do direito. Tradução de Jefferson Luiz Camargo. São Paulo: Martins Fontes, 1999 Levando os direitos a sério. Tradução de Nelson Boeira. São Paulo: Martins Fontes, 2002.

GALSTON, William A. liberal pluralism: the implications of value pluralism for political theory \& practice. Port Chester: Cambridge University Press, 2002.

GAUS, Gerald. Justificatory liberalism - an essay on epistemology and political theory. New York: Oxford University Press, 1996.

. Contemporary theories of liberalism. London: Sage Publications, 2003.

GÜNTHER, Klaus. Un concepto normativo de coherencia para una teoria de la argumentación jurídica. Tradução de Juan Carlos Velasco Arroyo. Doxa, p. 17-18, 1995.

GUTMANN, Amy. Rawls on the relationship between liberalism and democracy. In: FREEMAN, Samuel (Org.). Cambridge Companion to Rawls. Cambridge: Cambridge University Press, 2002.

HABERMAS, Jürgen. Direito e democracia: entre facticidade e validade. Tradução de Flávio Beno Siebeneichler. Rio de Janeiro: Tempo Brasileiro, 1997. v. 1.

Constitutional democracy: a paradoxical union of contradictory principles? Tradução de William Rehg. Political theory, v. 29, n. 6, dez. 2001.

- Três modelos normativos de democracia. Tradução de Paulo Astor Soethe. A inclusão do outro. Loyola:

São Paulo, 2002. Intolerance and discrimination. International journal of Constitutional Law, v. 1, n. 1, 2003. 
A inclusão do outro. Tradução de George Sperber, Paulo Astor Soethhe e Milton Camargo Mota. São Paulo: Loyola, 2004.

HARSANYI, John C. Morality and the theory of rational behaviour. In: SEN, Amartya; WILLIAMS, Bernard (Org.). Utilitarianism and beyond. Cambridge: Cambridge University Press, 1994.

KEKES, John. Morality of pluralism. Ewing: Princeton University Press, 1993.

KELSEN, Hans. A essência e o valor da democracia. A democracia. Tradução de Ivone Castilho Benedetti. São Paulo: Martins Fontes, 1993.

Teoria pura do direito. Tradução João Baptista Machado. São Paulo: Martins Fontes, 2000.

LUHMANN, Niklas. Sociologia do direito I. Tradução de Gustavo Bayer. Rio de Janeiro: Tempo Brasileiro, 1983.

RAWLS, John. The idea of an overlapping consensus. Oxford Journal of Legal Studies, v. 7, n. 1, Oxford: Oxford University Press, 1987.

. Political liberalism: reply to Habermas. The Journal of Philosophy, v. 92, issue 3, mar. 1995.

. O liberalismo político. Tradução de Dinah de Abreu Azevedo. Brasília: Ática, 2000.

As liberdades básicas e a sua prioridade. In: RAWLS, John. Justiça e democracia. Tradução de Irene

Paternot. Martins Fontes: São Paulo, 2002a.

- Uma teoria da justiça. Tradução de Almiro Pisetta e Lenita Maria Rimoli Esteves. 2. ed. São Paulo:

Martins Fontes, 2002b.

- Justiça como equidade - uma reformulação. Trad. Claudia Berliner. São Paulo: Martins Fontes, 2003.

ROSENFELD, Michael. The rule of law and the legitimacy of constitutional democracy. Southern California Law Review, v. 74, mar. 2001a.

. The rule of law and the legitimacy of constitutional democracy. Cardozo Law School, Public Law Research

Paper n. 36, mar. 2001b.

-A identidade do sujeito constitucional. Tradução de Menelick de Carvalho Netto. Belo Horizonte:

Mandamentos, 2003.

SCANLON, T. M. Rawls on justification. In: FREEMAN, Samuel (Org.). Cambridge Companion to Rawls. West

Nyack: Cambridge University Press, 2002.

SPATES, James. The sociology of values. Annual Review of Sociology, v. 9, 1983.

\section{Fábio Portela Lopes de Almeida}

SHCGN 703, Bloco H, Casa 30

Asa Norte - Brasília-DF

fabio.portelalagmail.com
Mestre em Direito, Estado e Constituição

ESPECIALISTA EM FILOSOFIA (AMBOS PELA UNIVERSIDADE DE BRASília)

Membro do Grupo de Trabalho em Mediação, Negociação e Arbitragem e do Grupo de Pesquisa Pensamento Social 